\title{
The Extent of the Inclusion of Listening Development Skills in my Beautiful Language Course for the Sixth Grade in the Kingdom of Saudi Arabia
}

\author{
Adel Abdullah Alkahtani ${ }^{*}$ and Eman Abdulaziz Aldoughan ${ }^{2}$ \\ 'University of Jeddah, Jeddah, Saudi Arabia; aalqahtani@uj.edu.sa \\ ${ }^{2}$ King Faisal University, Saudi Arabia; eadoughan@kfu.edu.sa
}

\begin{abstract}
Background/Objectives: To determine the degree of inclusion of listening development skills in 'My beautiful language course for the sixth grade in Saudi Arabia. Methods/Statistical Analysis: The present study attempts to answer the following main question: How well does listening development skills be included in my beautiful sixth grade course in Saudi Arabia? Also, the present study is trying to determine the degree of inclusion of listening development skills in my beautiful language course for the sixth grade Saudi Arabia. The researchers used the descriptive approach in the survey methodology, analyzing the content to describe the phenomenon as it is in fact by surveying the literature on the skills of language communication, especially listening skills. The study used 13 previous studies as a reference. Findings: The researchers found the following results: - The extent of inclusion of the skill of audio discrimination in the course of my beautiful language course in the sixth grade rate of $11.42 \%$ of the total skills of listening development. - The extent of inclusion of the skill of classification in the course of my beautiful language in the sixth grade $1.42 \%$ of the total skills of listening development. - The extent of the inclusion of reasoning skills in the course of my beautiful language in the sixth grade reached $14.28 \%$. Improvements/Applications: The researchers propose to study the extent to which listening development skills are included in my beautiful language course for the sixth grade and my beautiful language courses in all primary grades.
\end{abstract}

Keywords: Developing Listening Skills and Beautiful Language Course for the Sixth Grade

\section{Introduction}

The primary objective of teaching Arabic is to provide the learner with basic language skills: Listening, speaking, reading and writing. The listening is the first linguistic art that a person begins to communicate in the language, although importance of listening among the linguistic skills. The present study attempts to answer the following main question: How well does listening development skills be included in my beautiful language course for the sixth grade in Saudi Arabia? Also, the present study is trying to determine the degree of inclusion of listening development skills in my beautiful language course for the sixth grade in Saudi Arabia.

This study is useful in teaching listening development skills in my beautiful language course. The importance of this study can be determined in the following:

- Arabic Language Teacher: The study provides a list of listening development skills, which helps in teaching listening skills in my beautiful language course. It also helps in the process of: Deriving the objectives of the Arabic language lessons, choosing appropriate 
educational strategies, selecting the appropriate teaching methods and techniques, in the textbook.

- Preparation of the Arabic Language Curriculum: This study will help to include the skills of listening development in the course of my beautiful language in a logical and sequential manner. Where these skills will be in mind in the process of planning and preparation of Arabic language curricula. It will also facilitate the process of evaluating existing courses in the light of listening development skills.

- Researchers: Open the field for further research and studies to determine the skills of listening development in the curricula of teaching Arabic at all levels.

\section{Literature Survey}

The literature distinguishes the concept of listening between it and several concepts on gradual hierarchical considerations referred to by ${ }^{-}-\underline{-}$. The hearing that indicates as the arrival of the sound to the ear inadvertently and without attention and then listen; receive the sound and reach the ear with intent and attention, listening; receiving sound and reach the ear with the intention of intense attention and concentration and not interrupted by a break. The skill of listening is one of the means by which the person is keen to increase his/her culture and experience, as it is a skill that accompanies throughout one's life and the more he/she is a good listener, the better the understanding, and the correct of what is heard and draw conclusion and analysis ${ }^{4}$. By listening, the learner can acquire the language and a successful means for learners are to teach them the correct speaking in Arabic and reading and writing ${ }^{5}$. The main objective of development of listening is: "A description of a change in language behavior that is expected to occur from the student as a result of passing through various linguistic experiences and interacting with them in planned learning situations ${ }^{6}$.

- Developing the ability to recognize and distinguish voices.

- Develop the ability to listen, attention and focus on the audio material.

- Developing the ability to track audio.

- Training to understand audio in speed and accuracy.

- Inculcating habitual listening as an educational social value.

- Develop the taste side to choose the audio material.
- Development of rapid thinking and decisionmaking.

The basic skills for the development of listening to the primary stage in the branches of Arabic are represented by the following:-

- Audio discrimination includes sub-skills: Remembering, distinguishing the sounds of beginning, center and end, the ability to merge sounds and complete imperfection (closure).

- The skill of classification and focuses on the moral relations between words and facts and concepts and classification by similarity or integration.

- Deductive reasoning and require the extraction of the main ideas from the audible text and predict the results even if not spoken by the speaker.

- To judge the validity of the content of the audio evaluation and the statement of pros and cons.

- Evaluation of the speaker and the accuracy of his choice of words, expressions and emotions with the appropriate proposal of the words and concepts of the subject of modern (feedback) $)^{\underline{T}}$

To develop the listening skill, the learner should pass through five stages:-

- Receiving (reception of sound effects).

- Attention (focus on the words of the speaker or the voices he hears).

- Determination of meaning.

- Remembering (storing what he heard in his mind, so that it can be retrieved when necessary).

- Feedback (to ensure that the understanding of the audio, so that the listener is sent in the communication process when he responds to the speaker and give him some responsibilities)

There are many types of listening according to its various stages:

- Listening to (to enjoy) such as listening to music, anthem, stories or any art work on stage or listening to a lecture.

- Listening comprehension (hearing) to listen to a lesson or a scientific seminar or lecture in order to understand what is going on.

- Audited listening to a decision on the audible material. 
- Social listening, which is practiced by the individual in social situations.

- Therapeutic listening is a type used when listening to someone who is talking about a problem in trying to provide his best solution.

There are several types of listening according to the goal of listening and the researchers are likely to be three main types that can be used in the field of education, namely listening comprehension, criticism and taste.

The methods of teaching are not different from other skills, except the method of organizing the material, which depends on the functional communication towards: Apology, definition and this is the portal which gives the learner his needs in knowledge, so it is necessary to observe grammatical rules and methods of construction. There are several ways to teach listening, the goal of which is one: To train learners to listen, listen and understand the audio. Among the methods used in teaching, which differ from one teacher to another, is not harmful in this difference referred.

- The preamble and then instructs the teacher questions to listeners and discuss them about what was heard, whether the subject or short story and then shows the teacher to listeners some guidance on the ethics of listening.

- The teacher provides a suitable story for the pupils, in a language that suits them and after telling the story, the teacher asks the learners to provide a verbal summary of what they have learned about the audio, proposes a new title and devise the most prominent ideas.

- The teacher asks a good student to read a topic of reading and divides the class into groups, according to the nature of the topic, so that the large group is the one who is mandated to listen, achieve the main goal, while the smaller groups are assigned to the other sub-goals. Each group has reached the hearing of all.

Summarizing the above in three stages: The preparation stage, implementation and follow-up (feedback). $\mathrm{In}^{-}$indicated the effectiveness of using the representative activity to develop some of the listening skills in the Arabic language for the elementary school students, while ${ }^{9}$ pointed out the effectiveness of the activity and the method of the lecture. The researchers summarize the main fundamentals in teaching listening:-

- Remove distractions.
- Attention.

- Proper teaching.

- Attention to the main idea.

- Training in critical listening skills.

- Practice and continuous training.

The learner should have the ethics of listening to achieve effectiveness, so he summarized the ethics of hearing in the following:

- Do not interrupt who you listen to and participate in dialogue system.

- Do not prepare the reply in yourself and you hear the speaker and I was slow to respond to him.

- Do not explain everything you hear from your own point of view.

- Do not try to change the talk, because that hurts the speaker.

- Be careful to listen and to notify the speaker of the desire and the desire to listen to him.

- Smile to your news and showed signs of satisfaction and approval of what he says gestures and expressions in the eye and face using body language.

\section{How To Develop Listening Skill}

Hearing helps to achieve interaction, stimulate motivation among learners and can be developed through:

- Developing the ability to remember: So that the learner can link his current information, with the previous retained in memory; to evaluate and build a specific response to it.

- Benefit from the nature of the building provided to the learner: Which focuses on how the systems of the process of speech in line with individual differences between learners, as an input to understand others and determine the way to deal with them.

- Adhering to the guiding rules for good listening: Which requires the formation of habits of good listening to: attention to the speaker and away from distractions from environmental or psychological factors and follow verbal expressions and gestures used by the spokesman and respond to him and avoid the speed of judgments, assessment and conclusion.

- Focus on the skill of speaking after listening directly: It is through the knowledge of the ability of the learner to express positive attitudes when communicating with others ${ }^{10}$. 
It should be noted that its development requires conscious planning, which takes into account the nature of the learner, his psycho-social composition, classroom management, good planning of the listening lesson and positive psychological development.

- Classroom management: Everything related to the order of the learners in class according to their hearing abilities, the correct health session and motivates learners to automatic discipline.

- Good planning for the listening lesson: Requires a good choice of subject and suitability for learners and their interests and interests and the use of techniques that provide an atmosphere of pleasure and attention to human and Islamic and national and social trends and values and the involvement of learners in the selection of audio material and choose the most appropriate time to display the audio material, Auditory lesson.

- Positive psychological configuration: Linked to the vulnerability of the teacher and his keenness to promote a positive competitive environment between the learners, based on familiarity and affection and encourage them to talk and play roles and to provide some rare and party ${ }^{11}$.

In contrast, attention should be paid to the impediments to listening, which are influenced by a range of influences, notably:

- The linguistic wealth and the extent of the learner's outcome.

- The motivation and effectiveness of the learner during the listening process.

- The ability of the listener to organize his ideas based on his knowledge of the main ideas in the audible text.

- Methods and teaching methods used that help the listener to focus on what he hears.

- The gender of the listener is an important factor in determining the effectiveness of the communication process. Women are more able to recognize and interpret nonverbal messages, while men are more able to understand verbal messages than women.

- The health and psychological conditions of the listener have a strong impact on the effectiveness of the communication process, because the listener has a health problem in the ear, or anxiety, so it must be known to ensure effectiveness ${ }^{12}$.
- The social environment and its suitability to the effectiveness of the listener in term of calm, and the type of medium in which he lives Is it a catalyst or not.

The above constraints can be categorized in social, educational and social constraints. The foregoing can be summed up in the $\frac{13}{\underline{13}}$ that poor listening generates many problems during the communication process, leading to misunderstandings, conflicting opinions, loss of important information and frustration and the loss of opportunities in the development of relations at the personal and functional level.

\section{Research Methodology and Numerical Results}

To achieve the objective of the study, the researchers used the descriptive approach in the survey methodology, analyzing the content to describe the phenomenon as it is in fact by surveying the literature on the skills of language communication, especially listening skills.

- The tool: Content Analysis Card; to determine the extent to which listening development skills are included in my sixth language course in Saudi Arabia.

- Sample: The sample of the study consisted of the course of my beautiful language in the first semester and the second in the Kingdom of Saudi Arabia for the academic year 1439/1440 AH.

The researchers presented the study tool to a group of arbitrators to verify the apparent honesty of the tool. The results of this study were to add subtraction skill in the deductive reasoning skills: Instructing the student to understand the audible text in general. While the stability was calculated by re-analysis using the statement of the Cooper equation to calculate the coefficient of the agreement, and the results were as follows:

It is clear from the previous table that the coefficient of agreement between the first analyst and the second analyst was good at $53 \%$, so the tool is applicable. The following statistical methods were used:

- Duplicates of skills in the course.

- Percentages.

- SMA. 
- Cooper's equation; to calculate the stability of analysis.

The content analysis card consisted of four main skills and fourteen sub-skills. The results of the frequencies were adopted as follows:

Table 1. The coefficient of the agreement to calculate the stability of the analysis using the Cooper equation

\begin{tabular}{|c|c|c|c|}
\hline $\begin{array}{c}\text { Coefficient } \\
\text { of agreement }\end{array}$ & $\begin{array}{c}\text { Number } \\
\text { of times } \\
\text { difference }\end{array}$ & $\begin{array}{c}\text { Number } \\
\text { of times } \\
\text { agreed }\end{array}$ & Textbook \\
\hline $53 \%$ & 8 & 9 & $\begin{array}{c}\text { My } \\
\text { Beautiful } \\
\text { Language } \\
\text { (Second } \\
\text { Semester) }\end{array}$ \\
\hline
\end{tabular}

Table 2. Estimating the results of the frequencies

\begin{tabular}{|c|c|c|c|c|c|}
\hline $\begin{array}{c}\text { Not } \\
\text { Included }\end{array}$ & Weak & Average & Good & High & Evaluation \\
\hline Zero & $1-2$ & $3-4$ & $5-6$ & $7-10$ & $\begin{array}{c}\text { Repeation } \\
\text { number }\end{array}$ \\
\hline
\end{tabular}

It is clear from Table 3 that the skill of instructing the student to listen to the teacher when reading the audible text was repeated five times during my beautiful language in the first semester and repeated four times in the second semester. Repeat nine times. As for teaching the student to complete the main idea of the audible text was repeated once in the first semester, and once in the second semester, and therefore the proportion of the presence in the course was weak because it was repeated twice.
It is clear from Table 3 that the skill of instructing the student to listen to the teacher when reading the audible text was repeated five times in the textbook of my beautiful language in the first semester and repeated four times in the second semester. Repeat nine times. As for teaching the student to complete the main idea of the audible text was repeated once in the first semester, also; once in the second semester, and therefore the proportion of the presence in the textbook was weak because it was repeated twice.

The skill of instructing the student to distinguish between the audible and readable text was read in a normal manner three times in the first semester and twice in the second semester, so that the rate of its presence in the textbook was good because it was repeated five times. While the skill of instructing the student to memorize the audible text is a skill not included in the textbook because it does not exist. The focus of the textbook is on keeping the reading text in the poetic text, which is repeated three times in the first semester in each unit of the book once, The second was repeated three times in each unit of the book once, so the total presence of the skill of memorizing the readable text was six times by a good presence. In general, the percentage of the main skill (audio discrimination) in the decision was $11.42 \%$, with an average of 1.14 .

It is clear from Table 4 that the skill of instructing the student to distinguish between the sounds of the letters at the beginning, the middle and the end of the speech is a skill that is not included in the decision because it does not exist.) Once in the first semester was the focus on the actions only without the letters and names, so the proportion of the presence in the textbook was weak;

Table 3. The extent of the inclusion of the skill of audio discrimination in the course of my beautiful language in the sixth grade

\begin{tabular}{|c|c|c|c|c|c|c|c|}
\hline \multicolumn{4}{|c|}{ Extent of inclusion } & Sub-Skills & Main skill & Serial \\
\hline Not-Included & Weak & Average & Good & High & & 1 \\
\hline & 2 & & & 9 & $\begin{array}{c}\text { Instruct the student to listen to the teacher } \\
\text { when reading the audio text. }\end{array}$ & & 2 \\
\hline & & & 5 & & $\begin{array}{c}\text { Instruct the student to complete the main } \\
\text { idea of the missing audible text. }\end{array}$ & \multirow{2}{*}{$\begin{array}{c}\text { Audio } \\
\text { disstruct the student to distinguish } \\
\text { between the audible text, which is read in } \\
\text { a representative manner, and is read in a } \\
\text { normal way. }\end{array}$} & 3 \\
\hline 0 & & & & & $\begin{array}{c}\text { Instruct the student to save the } \\
\text { audible text. }\end{array}$ & & \\
\hline
\end{tabular}


Table 4. The extent of inclusion of the skill of classification in the course of my beautiful language in the sixth grade

\begin{tabular}{|c|c|c|c|c|c|c|c|}
\hline \multicolumn{5}{|c|}{ Extent of inclusion } & \multirow{2}{*}{ Sub-Skills } & \multirow{2}{*}{ Main skill } & \\
\hline Not-Included & Weak & Average & Good & High & & & \\
\hline \multirow[t]{3}{*}{$\mathbf{0}$} & & & & & $\begin{array}{l}\text { Instruct the student to distinguish between the } \\
\text { sounds of the letters at the beginning of the } \\
\text { speech and in the middle and end. }\end{array}$ & \multirow{3}{*}{ Classification } & 5 \\
\hline & 1 & & & & $\begin{array}{l}\text { Instruct students to classify spoken words into } \\
\text { their main elements (letters, verbs, names). }\end{array}$ & & 6 \\
\hline & 1 & & & & $\begin{array}{l}\text { Instruct the student to classify the spoken words } \\
\text { according to similarities and differences in } \\
\text { meaning. }\end{array}$ & & 7 \\
\hline
\end{tabular}

Table 5. The extent to which deductive thinking is included in my sixth grade syllabus

\begin{tabular}{|c|c|c|c|c|c|c|c|}
\hline \multicolumn{5}{|c|}{ Extent of inclusion } & \multirow{2}{*}{ Sub-skills } & \multirow{2}{*}{ Main skill } & \\
\hline Not-Included & Weak & Average & Good & High & & & \\
\hline & & & & 17 & $\begin{array}{l}\text { Instruct the student to understand the audible } \\
\text { text in general. }\end{array}$ & \multirow{4}{*}{$\begin{array}{l}\text { Deductive } \\
\text { reasoning }\end{array}$} & 8 \\
\hline & 1 & & & & $\begin{array}{l}\text { Instruct the student to extract the main idea } \\
\text { from the audible text. }\end{array}$ & & 9 \\
\hline & 2 & & & & $\begin{array}{l}\text { Instruct the student to place a new title for the } \\
\text { audio text. }\end{array}$ & & 10 \\
\hline $\mathbf{0}$ & & & & & $\begin{array}{l}\text { Instruct the student to clarify the main idea of } \\
\text { the audible text. }\end{array}$ & & 11 \\
\hline
\end{tabular}

because it was repeated only once and focused on only one part of the speech acts, as well as the skill of instructing the student to classify the words According to similarities and differences in meanings $Z$, which was repeated only once in the first semester in the statement of similarities and differences in color naming, and therefore the proportion of their presence is also weak, because of their lack of presence in the textbook. Overall, the percentage of the skill of classification in the textbook of my beautiful language was $1.42 \%$, with an average of 0.14 .

It is clear from Table 5 that the skill of instructing the student to understand the audible text in general has been repeated nine times in the first semester, three in the targeted competencies in each unit of the book in the first semester, in the correction activity, Eight in the second semester, three in the targeted competencies in each of the three units of the three books, in multiple choice activity, an understanding and answer activity, correcting activity, and answering activity. Therefore, its presence was high; 17) once in two chapters. While the skill of instructing the student to extract the main idea from the audible text once again in the first semester, and therefore its presence was weak because it repeated in the textbook once. The repetition of the skill of instructing the student to develop a new title for the audio text once in the first chapter, and the same in the second semester, and therefore the presence of skill in the textbook was weak; because it repeated only twice. The skill of instructing the student to clarify the main idea of the audible text is a skill not included in the textbook. Overall, the percentage of reasoning skills in the textbook was $14.28 \%$ and an average of 1.42 .

It is clear from Table 6 that the skill of instructing the student to indicate the positives in the method used in the listening activity, and the skill of instructing the student to explain the negatives in the method used in the listening activity are not included in the decision, while the skill of instructing the student to evaluate the audible text My average language was repeated three times in the first semester and once in the second semester. Therefore, the 
Table 6. The extent to which the skill of judging the validity of the content in the course of my beautiful language in the sixth grade

\begin{tabular}{|c|c|c|c|c|c|c|c|}
\hline \multicolumn{5}{|c|}{ Extent of inclusion } & \multirow[b]{2}{*}{ Sub-skills } & \multirow{2}{*}{ Main Skill } & \\
\hline Not-Included & Weak & Average & Good & High & & & \\
\hline 0 & & & & & $\begin{array}{l}\text { Instruct the student to demonstrate the } \\
\text { positives in the method used in the listening } \\
\text { activity. }\end{array}$ & \multirow{3}{*}{$\begin{array}{l}\text { Judging the } \\
\text { truthfulness of } \\
\text { the content }\end{array}$} & 12 \\
\hline \multirow[t]{2}{*}{0} & & & & & $\begin{array}{l}\text { Instruct the student to explain the negatives in } \\
\text { the method used in the listening activity. }\end{array}$ & & 13 \\
\hline & & 4 & & & $\begin{array}{l}\text { Instruct the student to evaluate the audible text } \\
\text { in the textbook of my beautiful language. }\end{array}$ & & 14 \\
\hline
\end{tabular}

skill presence was moderate because it was repeated four times in the two semesters. Overall, the ratio of the skill of judging the validity of the content was $2.85 \%(0.28)$.

Table 7. The extent to which listening development skills are incorporated into my sixth language course

\begin{tabular}{|c|c|c|c|}
\hline Average & Percentage & Main Skill & \\
\hline 1.14 & $11.42 \%$ & Audio discrimination & $\mathbf{1}$ \\
\hline 0.14 & $1.42 \%$ & Classification & $\mathbf{2}$ \\
\hline 1.42 & $14.28 \%$ & Deductive reasoning & $\mathbf{3}$ \\
\hline 0.28 & $2.85 \%$ & $\begin{array}{c}\text { Judging the } \\
\text { truthfulness of the } \\
\text { content }\end{array}$ & $\mathbf{4}$ \\
\hline & $29.97 \%(30 \%)$ & Sum \\
\hline
\end{tabular}

Extrapolation from the data shown in Table 7 shows that the inclusion of skills in the textbook was weak, but did not exceed 30\%. In general, the inclusion of the previous skills in the textbook was a traditional activity and not attractive to primary school students. Programs, skills and different arts to develop listening skills. The results of many studies have been proven in the study of Al-Nasir (2008), in which he found that the curriculum is suitable for teaching the ability to speak in an integrated manner with the skills of linguistic communication. Al-Shanti study (2010), in which he reached the effectiveness of the representative activity to develop some listening skills in the Arabic language, and recommended a balance in evaluating the skills of the Arabic language. In the research and according to the scientists' knowledge - until the time of preparation of this paper, there is no scientific study that used the content analysis in the statement of the inclusion of listening development skills in the textbook, which may distinguish this study from others.

\section{Concluded Comments and Recommendations}

The researchers found the following results:

- The extent of inclusion of the skill of audio discrimination in the course of my beautiful language in the sixth grade rate of $11.42 \%$ of the total skills of listening development.

- The extent of inclusion of the skill of classification in the course of my beautiful language in the sixth grade $1.42 \%$ of the total skills of listening development.

- The extent of the inclusion of reasoning skills in the course of my beautiful language in the sixth grade reached $14.28 \%$.

- The extent of the inclusion of the skill of judging the validity of content in the course of my beautiful language in the sixth grade $2.85 \%$.

- The reasoning skill of the listening development skills exceeded $14.28 \%$ in total, followed by the skill of audio and in-built discrimination by $11.42 \%$ in the course my beautiful language in the sixth grade.

- Poor inclusion of listening development skills in general in the course of my beautiful language in the sixth grade.

The researchers recommend:

- Attention to include the skills of listening development in the course of my beautiful language in the sixth grade.

- To promote the inclusion of the skill of audiovisual discrimination in activities in the course of my beautiful language in the sixth grade.

- To enhance the inclusion of the skill of classification in activities in the course of my beautiful language in the sixth grade. 
- To enhance the inclusion of reasoning skills in activities in the course of my beautiful language in the sixth grade.

- Promote the inclusion of the skill of judging the veracity of the content in the activities of the course of my beautiful language in the sixth grade.

Based on the above, the authors proposed listening development skills are included in my beautiful language course and my beautiful language courses in all primary grades.

\section{Acknowledgement}

This paper has been presented and discussed during the International Conference on Communication, Management and Information Technology- ICCMIT 2019, Vienna, Austria.

\section{References}

1. Shanab A, Ahmed M, Al-Otaibi, Kazim F. Problems of language communication. Academic Writing Center: Amman; 2015.

2. Al-Ramini, Fathallah F. Scrutiny in the standards of Arabic language arts and teaching methods based on the learner. University Book House: UAE; 2009.

3. Ahmed Fouad A. Language skills and methods of tuning. 2000.
4. Mohammed Jihad J, Samar Rouhi A. Communication skills in Arabic Language. University Book House: UAE; 2015.

5. Abdel Salam Youssef J. Teaching Arabic in the light of modern trends. University Book House: UAE; 2014.

6. Mohammed Abdul Aziz A, Hoda Mohammed S. Modern trends in teaching Arabic grammar and applications. Dar Al-Zahra: Riyadh; 2012.

7. Ibrahim Mohammed A. Linguistic listening and educational demands. Book Center: Cairo; 2009.

8. Faiza al-Sayyid A, Al-Bustami, Du'aa Abuzaid. Guide in teaching Arabic language. Al-Rashed Library: Riyadh; 2009.

9. Iman Abbas A. The linguistic development of the family, the teacher and the university researcher. Arab Community Library: Amman; 2014.

10. Ali Ahmed M. Teaching Arabic language arts. Arab Thought House: Cairo; 2014.

11. Safe Healing Y. Arabic communication skills between talent and acquisition. Research published in the Fifth International Conference on Arabic Language; Dubai. 2016.

12. Banham K. Methods and methods of Teaching Arabic language proficiency a descriptive and analytical study in the light of the book of the Fourth International Conference on the Arabic Language. Research published in the journal Hijaz International Court for Islamic and Arabic Studies; 2011. p. 613-56.

13. Amiraa Abdulrahman S. The impact of the use of representative activity to develop some listening skills in the Arabic language among the fourth grade pupils in Gaza. [Unpublished Master Thesis]. Al-Azhar University: Gaza; 2010. 